$\underline{\text { Original Article }}$

\title{
FORMULATION AND EVALUATION OF GLIBENCLAMIDE GEL FOR TRANSDERMAL DRUG DELIVERY
}

\author{
NOSHEEN ANWAR ${ }^{1,2}$, SYED UMER JAN², REHMAN GUL1,2* \\ 1Department of Pharmaceutics, Faculty of Pharmacy and Health Sciences University of Balochistan, Quetta, Pakistan, ${ }^{2}$ Department of \\ Health Government of Balochistan, Quetta, Pakistan \\ Email: gul.dotani@yahoo.com \\ Received: 17 Jun 2020, Revised and Accepted: 16 Aug 2020
}

\begin{abstract}
Objective: The purpose of the recent study was to formulate glibenclamide gels for transdermal drug release, and to evaluate the oleic acid effect on the release of the preparations.

Methods: Oleic acid was used at a range of concentrations in the gel formulations and its effects observed in Glibenclamide gel using In vitro release of drug was done in Franz diffusion cells, whereas pH 7.4 Phosphate buffer was used for release studies. Formulations were characterized by clarity, pH, homogeneity, viscosity, spreadabilty, skin irritation, drug content, stability studies. Scanning calroimetry analysis (SCA) and XRD studies were
\end{abstract} performed to assess the physical and chemical interactions.

Results: Release profiles in vitro were observed. The released quantity of drug recovered from the glibenclamide gel after the addition of $1 \%$ oleic acid, increased with increasing concentration of the enhancer that is oleic acid. Whereas drug quantity recovered in the receptor solvent was $69.999 \%$ of Glibenclamide gel having 3\% oleic acid. All the formulation were physicochemically stable. The data was statistically analyzed by using SPSS and DD solver.

Conclusion: The drug is released and the oleic acid does enhance the release of the drug with the increase in its concentration.

Keywords: Glibenclamide, Oleic acid, Transdermal gel, Carbopol 934

(C) 2020 The Authors. Published by Innovare Academic Sciences Pvt Ltd. This is an open access article under the CC BY license (http://creativecommons.org/licenses/by/4.0/) DOI: http://dx.doi.org/10.22159/ijcpr.2020v12i5.39762. Journal homepage: https://innovareacademics.in/journals/index.php/ijcpr

\section{INTRODUCTION}

Glibenclamide is a second generation sulphonyl urea oral hypoglycemic agent, chemically it is1-[4-[2-(chloro 2-methoxybenzamido) ethyl]benzenesulphonyl]-3cyclohexylurea, 5-chloro-N-[2-[4-[[[(cyclohexyl (amino) carbonyl]-amino] sulphonyl] phenyl] ethyl-2-methoxy benzamide. It is more potent than first generation sulphonylurea. GLB is also called as glyburide and its formula is $\mathrm{C}_{23} \mathrm{H}_{28} \mathrm{CIN}_{3} \mathrm{O}_{5} \mathrm{~S}$ [1].

Plasma $1 / 2$ life of GLB about 4-6 h. Which enhance therapeutic effectiveness and keep steady plasma level. Transdermal application of GLB avoiding the hypoglycemic episode which are concomitant by oral GLB administration [2].

GLB has shown several adverse and potential side effect related to hypoglycemia with in accurate dossing. However, the side effects of GLB with this formulation and oral administration are quite common. It is demonstrated that GLB can cause gastrointestinal side effects including nausea, vomiting, anorexia, and heart burn and increase appetite. It can cause severe hypoglycemia through direct effect on the pancreatic cells of islets to inhibit production of glucagon and increased release of somatostatin [3].

Transdermal drug delivery mechanism is most promising one. It has been demonstrated that medicines administered by this method has improved bioavailability with less side effects. It ensures controlled release of drug and deliver it directly to blood circulation. At the same time, the side effects are considerably reduced. As drug does not come in contact with stomach surface, there is no gastrointestinal irritation and side effects thus increasing drug compliance. The process is painless, drug does not go through usual metabolism in liver thus no adverse effects on liver. Most important impact is long availability of required serum levels which may result in decrease frequency of medicine. As a result of all above, TDD is becoming famous method of drug administration for increasing number of medicines $[4,5]$.

Gels are defined as semisolid preparation consisting either hydrophobic or hydrophilic an external solvent phase, and inside the three D complex spaces these are restrained. On the bases of solvent phase gels are of two type, organogels in which external solvent is an organic solvent, and hydrogels in which external solvent is water. Gels are widely used in different field of life such as cosmetics, foods, pharmatechnology, etc. According to the resent researches some other new types of gels are described for topical and TDD for example proniosomal gels, emulgels, bigels and aerogels [6].

The Diabetes is a metabolic disease that occurs when pancreas that is a gland become inactive and does not produce a hormone called insulin or pancreas produces less quantity of insulin due to which level of glucose in blood is increased. The level of glucose is controlled by insulin. Diabetes is a lifetime disease. Until now, there is no treatment. People with this disease must change their life style, eating habits and do exercise properly in this way they controlled their disease and live a healthy life (Available at Hangtide. com).

Diabetes is a serious complex condition associated with decrease insulin production which cause increase glucose level in blood. Glibenclamide is powerful $2^{\text {nd }}$ generation sulfonylurea derivative that is widely used in type 2 diabetes mellitus treatment $[7,8]$.

The purpose of this study was to design and evaluate transdermal GLB gel in combination of HPMC and carbopol 934 to increase permeation of GLB. It is proved that all oral side effects of GLB can be avoided by TDD, because drug is absorbed directly into blood stream via skin and reaches the target cell. In addition, by this method the drug has sustained release which reduces the frequency of dosage. The TDD thus can be a better preferred method of GLB administration.

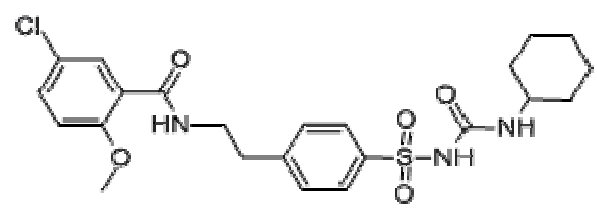

Fig. 1: Chemical structure of glibenclamide 


\section{MATERIALS AND METHODS}

\section{Chemicals}

Glibenclamide was received from Merck, martindow Germany, Triethanolamine, Methyl paraben and Propyl paraben (Merck, martindow Germany), Carbopol 934 NF polymer (Lubrizol, USA), Sodium dihydrogen phosphate, Disodium hydrogen phosphate, $\mathrm{NaOH}$, Polyoxyethylene (80) Sorbitan monooleate (Tween 80) (Merck, Germany), Distilled water (Medilines Diagnostic division), Oleic acid, Ethanol. All other chemicals were commercially available products of analytical grade.

\section{Apparatus}

Conical flask $50 \mathrm{ml}, 100 \mathrm{ml}$ (Pyrex, Germany), Pipette $5 \mathrm{ml}, 10 \mathrm{ml}$ (Preciclolor, Germany), Glass beaker $25 \mathrm{ml}, 50 \mathrm{ml}, 100 \mathrm{ml}$ (Pyrex, England), spatula, Aluminum collapsible tubes, White colored glass jar, Amber colored glass jar and Aluminum foil.

\section{Instruments}

Digital weighing balance (Sartorious, Analytical grade), $\mathrm{pH}$ meter (Model No: 3510, Germany), UV-Spectrophotometer double beam (Shimadzu 1601, Japan), Homogenizer (Euro-Star, IKA D 230, Germany), Franz diffusion Cell USP XXVII, Auto Reverse Magnetic
stirrer/Hot plate (Made of Germany), Magnetic Stirrer (made of England), Brookfield digital viscometer (model DV-III+, Brookfield Engineering Laboratory, INC. USA), XRD, Tewameter SEM, water distillation apparatus (AUTOSTIU Freshman-4).

\section{Preparation of GLB gel with permeation enhancers}

$1 \% \mathrm{w} / \mathrm{w}$ GLB gels were formulated along with permeation enhancer Oleic acid consuming Carbopol 934 (table 1). GLB and both permeation enhancer were dissolved in ethanol and then polymers weighed and dispersed in distilled water. Polymers solution were kept under continuous stirring. After that GLB and permeation enhancer solution and Carbopol 934 solution mixed together on other hand GLB and permeation enhancer solution together. Both dispersion were kept under continuous stirring until getting homogenous dispersion. TEA is used to neutralize prepared gels to the skin PH 7.4. Both gels were kept overnight for removal of any trapped air in the gel [9].

\section{Evaluation of gels}

\section{Clarity}

Visual analysis is determined with the help of black and white background $[9,10]$.

Table 1: Formulation of glibenclamide gel

\begin{tabular}{|c|c|c|c|c|c|}
\hline Formulation No. & GLB (gm) & Carbapol (gm) & Oleic acid (ml) & Ethanol (ml) & Triethanolamine (ml) \\
\hline F1 & 1 & 1 & Blank & 10 & 100 \\
\hline F2 & 1 & 1 & 1 & 10 & 100 \\
\hline F3 & 1 & 1 & 2 & 10 & 100 \\
\hline $\mathrm{F} 4$ & 1 & 1 & 3 & 10 & 100 \\
\hline
\end{tabular}

\section{Homogeneity}

It is done by visual inspection of homogeneity, color and occurrence of any lump after setting of gels in the containers [9-11].

\section{Spreadability}

Spreadability test is performed by the use of two glass slides in between gel is pressed. In this process, $0.5 \mathrm{~g}$ formulation was kept over first glass slide and second slide of $10 \mathrm{~g}$ was kept over the first slide. The diameter of spreaded circle would be measured and defined spreadability $[9,11]$.

\section{PH}

With the help of digital $\mathrm{pH}$ meter the $\mathrm{pH}$ of the all gels formulations are measured $[9,11]$.

\section{Analytical method}

From various formulations of gels the required and exact amount of gels are weight and dissolved in suitable solvent in volumetric flask. The resulting Solution is then filtered with the help of membrane filter of $0.45 \mu \mathrm{m}$ and absorbent are measured using by UV. Spectrophotometer at $300 \mathrm{~nm}[9,11,12]$.

\section{Rheological properties of gel}

By using Brookfield R/S+RHEOMETER viscosity of different gels formulation are measured $[12,13]$.

\section{Skin irritation study}

Animal study was approved by the reserach committee of the FPHS (Protocol/Reference number: ERC/003/01/2020). For this study rabbit was used. The rabbit skin hair was shaved over an area just about $6 \mathrm{~cm}^{2}$. The prepared Glibenclamide gels were applied on shaved area of rabbit skin and covered with a semi-occlusive gauze patch for about $1 \mathrm{hr}$. Afterward one hour, the left over gel was removed without skin ruptured then observed any response or sensitivity. The gel was applied one time in a day for week. All observations are listed as in table $2[9,11]$.

\section{SEM}

The surface morphology of GLB topical gel was determined through Scanning electron microscopy. SEM studies were done to define morphology and shape and along with checking particle size. For SEM measurements, prepared formulation by using double sided adhesive tape were attached on metal stub. Then it was dried in a vacuume chamber and sputter-coated with $10 \mathrm{~nm}$ thick gold layer and observed under a high resolution SEM (JSM-840, Joel Instrument, Tokyo, Japan) $[14,15]$.

\section{XRD}

X-ray powder diffraction is fast and non-destructive analytical technique basically used to analyze the structure of crystalline material. The crystalline phases present in a material recognized by the used of XRD, thus reveal chemical composition information. To compare with pure drug and physical mixture samples were exposed for power XRD studies. Powered X-rays diffractograms were taken as $5^{\circ} \mathrm{C}$ to $50^{\circ} \mathrm{C}$ at $2 \theta$ to study crystalline and amorphous nature of GLB $[15,16]$.

\section{In vitro diffusion study protocol}

In vitro diffusion studies of the Glibenclamide gel Franz diffusion cell apparatus (Perm Gear, USA) along with cellulose membrane was used. In between the receptor chamber and donor chamber of the Franz diffusion cell equipment the membranes were set. The receptor compartment was filled with approximately $5 \mathrm{ml}$ Phosphate buffer of $7.4 \mathrm{pH}$, whereas the donor compartments were filled with glibenclamide gel without enhancer as a blank, and the gels containing $1.0 \%, 2.0 \%$, and $3.0 \%$ oleic acid. Throughout the study temperature of the solvent was a constant that is $37{ }^{\circ} \mathrm{C}$. Samples of almost $1.0 \mathrm{ml}$ at $0.5,1,1.5,2,3,4,8,12,16,20$, and $24 \mathrm{~h}$ were taken from the receptor cells, and immediately refilled the cells with fresh buffer at $37^{\circ} \mathrm{C}$. The taken samples were filtered and the concentration of glibenclamide was calculated using the UV-visible spectrophotometer at $242 \mathrm{~nm}$ [17-19].

\section{Kinetic analysis of glibenclamide in vitro release}

The extent of Glibenclamide released in vitro diffusion studies was calculated, then linear regression analyses in addition, drug release parameters for all formulae were evaluated. For all formulae the correlation coefficient $\left(R^{2}\right)$ was calculated, to define which kinetic models related to drug release through cellulose membrane. Kinetic equations were used for the calculations given below [17-19]. 
Zero-order model: $\mathrm{A}=\mathrm{K} 0 \mathrm{t}+\mathrm{A}_{0}$

First-order model: $\log \mathrm{A}=\mathrm{Kt} / 2.3+\log \mathrm{A}_{0}$.

Higuchi-diffusion model: $\mathrm{Q}=\mathrm{K}_{\mathrm{H}} \mathrm{t}^{1 / 2}$

Korsmeyer-Peppas model: $\mathrm{C}_{\mathrm{t}} / \mathrm{C} \infty=\mathrm{Kt}^{\mathrm{n}}$

Hixson-Crowell diffusion release model: $\mathrm{Q}_{\mathrm{t}} \mathrm{Q}=\mathrm{Kt}^{\mathrm{n}}$

\section{Stability studies of GLB gel}

For stability studies, estimation the formulations maintained at ambient temperature over the period of $3 \mathrm{mo}$. All physical test as $\mathrm{pH}$ measurement, viscosity, homogeneity, drug assay are performed after three months of prepared topical gel formulations. It has analyzed through UV-Visible spectrophotometer $[9,11]$.

\section{Statistical analysis}

Enova test would be used to compare the effect of artificial membrane using SPSS software and DDsolver for drug release kinetic for transdermal gel. Different kinetic model would be used [17-19].

\section{RESULTS AND DISCUSSION}

All GLB topical gel formulations were clear, white and opaque after visual analysis and exhibited good homogeneity without lumps. Which revealed that the texture of formulated gels were clear and homogeneous. All gel formulations $\mathrm{pH}$ were in the range of 6.3 to 6.7 (table 2). Hence the gels were ideal and acceptable for topical application. Viscosity is an important factor that affects the spreadability and release of the drug. Viscosity of formulations were ranges between A-B cps (table 2). For topical preparation spreadability is one of the important factor and Gel is considered to be good if it takes minimum time to spread on the surface. The spreadability results varies from 4.8 to $6.6 \mathrm{~g}$. $\mathrm{cm} / \mathrm{s}$ (table 2). All the stabily stduies and gel formulations drug content was in the range of $97.10 \%$ to $98.19 \%$ (table 2), Showing content uniformity.

\section{In vitro drug diffusion study}

The Korsmeyer-Peppas permeation model was used for application of all formulation data. The release of Glibenclamide via the cellulose membrane from the transdermal gel, are shown in (fig. 2). All results revealed that the released drug quantity from the gel without oleic acid was lowest, with only $27.91 \%$ recovered in the receptor solvent after $24 \mathrm{~h}$ during cellulose membrane study. The released quantity of drug recovered from the glibenclamide gel after the addition of $1 \%$ oleic acid, increased with increasing concentration of the enhancer that is oleic acid. Whereas drug quantity recovered in the receptor solvent was $69.999 \%$ of Glibenclamide gel having $3 \%$ oleic acid. Other studies have showed that drug diffusion can increased by the presence of an essential oil. Higher the oleic acid concentration higher the release of drug [20].

Table 2: Physical parameters values for glibenclamide gel formulations

\begin{tabular}{|c|c|c|c|c|c|}
\hline $\begin{array}{l}\text { Glibenclamide gel with oleic acid at } \\
\text { various concentrations }\end{array}$ & pH & $\begin{array}{l}\text { Spreadability } \\
\text { (g. cm/s) }\end{array}$ & Homogeneity & Skin irritation & Drug content (\%) \\
\hline Blank & 5.3 & 4.4 & Good & Not any & 97.10 \\
\hline 1.0 & 5.2 & 4.6 & Good & Not any & 98.19 \\
\hline 2.0 & 6.3 & 4.7 & Good & Not any & 97.11 \\
\hline 3.0 & 5.2 & 5.4 & Good & Not any & 98.00 \\
\hline
\end{tabular}

All results values are mean of, $(n=3)$

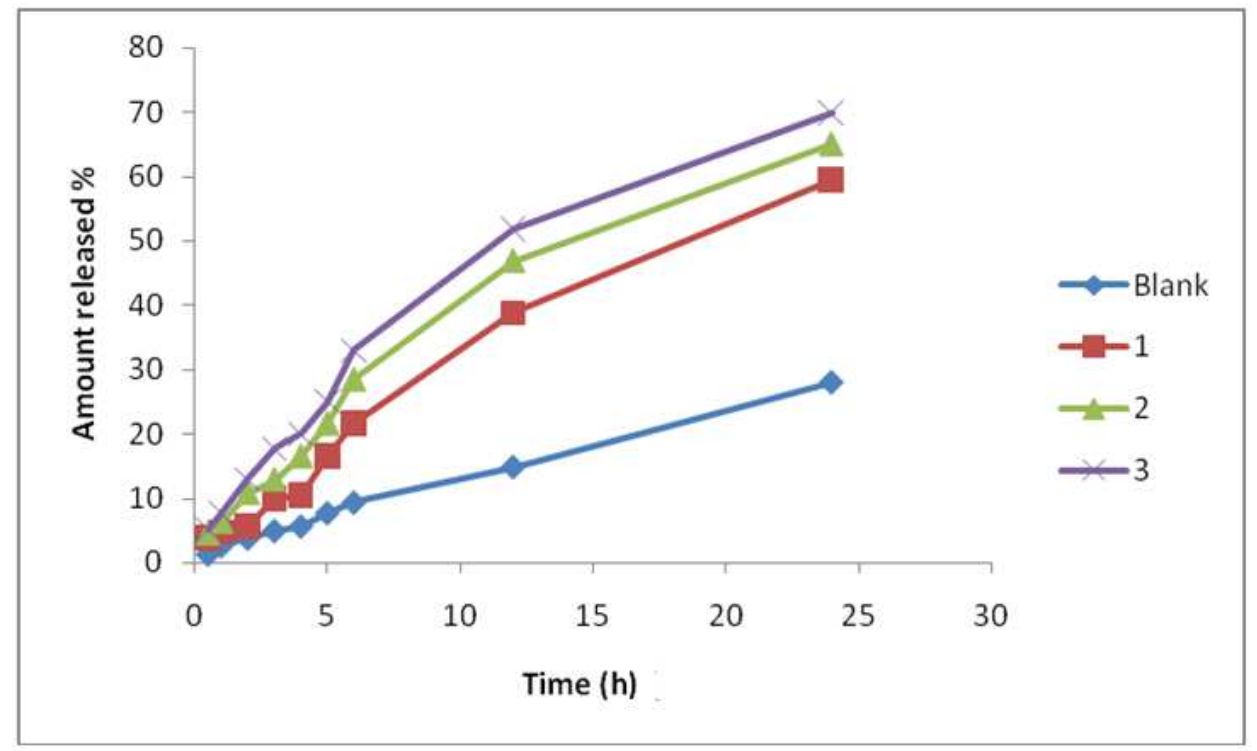

Fig. 2: Relesae of glibenclamide gel $1 \%(\mathrm{~W} / \mathrm{V})$ via cellulose membrane

\section{XRD studies}

To check physical and chemical properties of GB X-ray diffraction studies were applied and polymeric matrix of Gel formulation, B showed sharp peaks of diffraction at an angle of $2 \theta$ value of $13.52^{\circ}$, $18.23^{\circ}$, and $21.18^{\circ}$, etc. X-ray diffractograms are shown in (fig. $3, \mathrm{~A}$ ) that show crystalline nature of GB. While the fig. 3(C) blank showed no peaks, displayed peaks having lesser intensity, while the fused peaks were present in diffractograms of the GB gel. Irregular peaks of GB demonstrated that drug changed into an amorphous type in polymeric drugs with molecularly discrete nature. Which was reported by samiullah et al. previously [13]. 


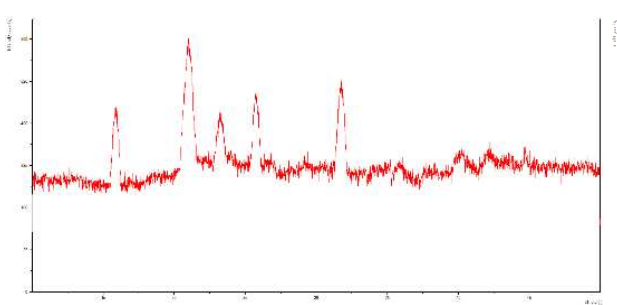

(a)

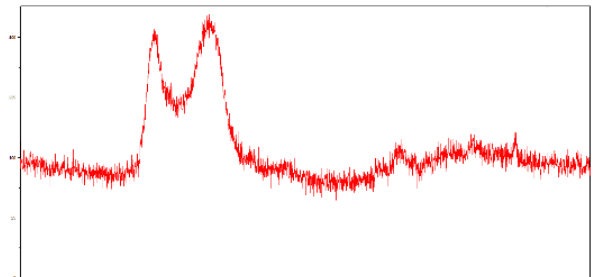

(b)

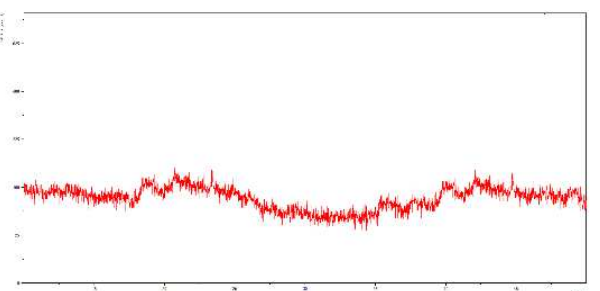

(c)

Fig. 3: X-ray diffractograms of (A) pure Glibenclamide (B) loaded glibenclmide polymeric gel, and (C) Blank gel

\section{SEM}

Morphology and size of the prepared GB gel was determined by using scanning electron microscopy. SEM images of different prepared GB gel were taken. SEM images had shown that GB fig. 4(A) gel had big crystal like shape in most of the pure drug, while shape of fig. 4(B) as shown Inside of gel formulation showed small white spots were present, which indicate that drug was loaded in gel and distributed within gel formulation.

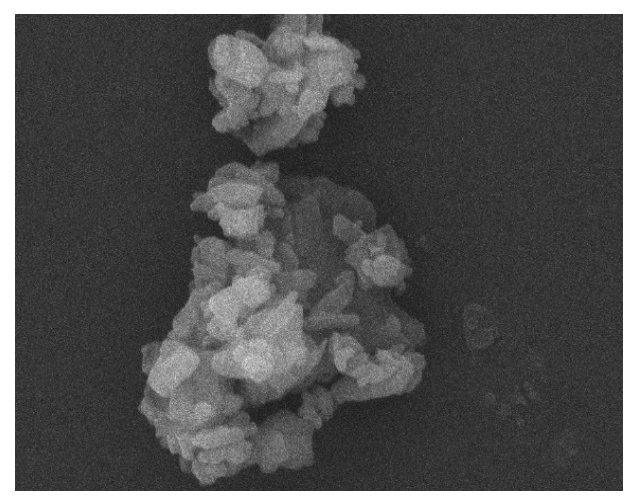

A

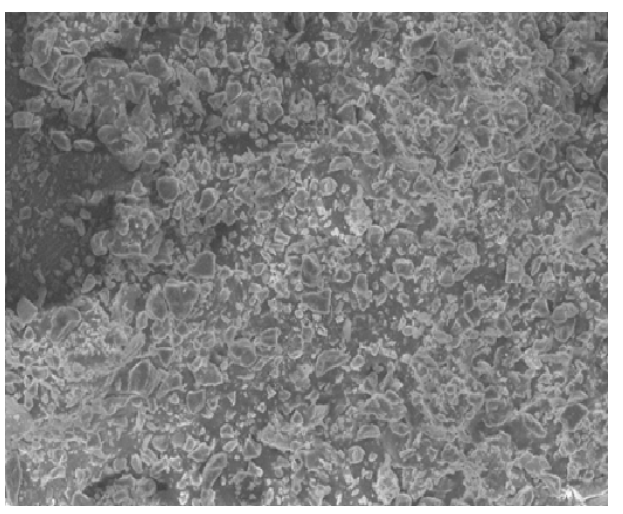

B

Fig. 4: (A) Illustrates surface morphology of the drug, while (B) display surface morphology of polymeric gel at different magnification powers stability studies of GLB gel

\section{CONCLUSION}

Glibenclamide topical gel was successfully formulated with permeation enhancer. Oleic acid help in the penetration of Glibenclamide into the cellulose membrane effectively. So oleic acid is effective and efficient enhancer at higher concentrations for drug permeation through the transdermal route. It is also concluded that Glibenclamide gel is suitable for topical application with a high in vitro release rate.

\section{ACKNOWLEDGEMENT}

The Authors would like to thank the members of the Faculty of Pharmacy and Health Sciences at the University of Balochistan for their timely support to complete this research.

\section{FUNDING}

Nil

\section{AUTHORS CONTRIBUTIONS}

All the authors have contributed equally.

\section{CONFLICT OF INTERESTS}

We have no conflict of interest.

\section{REFERENCES}

1. Tengli AR, Gurupadayya BM, Soni N, Vishwanathan B. Method development and validation of metformine, pioglitazone and glibenclamide in tablet dosage form by using RP-HPLC. Biochem Anal Biochem 2003;2:130.

2. Yamamoto T, Okumura M, Washiyama A. Re: topical application of glibenclamide lowers blood glucose levels in rats. Diabetes Res Clin 1990;1:19-22.

3. Mutalik S, Udupa N, Kumar S, Agarwal S, Subramanian G, Ranjith AK. Glipizide matrix transdermal systems for diabetes mellitus: preparation, in vitro and preclinical studies. Life Sci 2006;16:1568-77.

4. Ghosh TK, Pfister WR, Yum SI. Transdermal and topical drug delivery systems. Informa Health Care; 2004.

5. Hadgraft J, Guy R. In; Transdermal drug delivery, marcel dekker, Inc, New York and Basel; 1989. p. 1-17.

6. Rehman K, Zulfakar MH. Recent advances in gel technologies for topical and transdermal drug delivery. Drug Dev Ind Pharm 2014;4:433-40.

7. Davis SN, Granner DK. Insulin, oral hypoglycemic agents, and the pharmacotherapy of the endocrine pancreas. In Hardman JG, Limbird LE. (eds) The pharmacological basis of therapeutics. 9th ed. McGraw-Hill Co, New York; 1996. p. 1487-517. 
8. Nolte MS, Karam JH. Pancreatic harmones and antidiabetic drugs. In: Katzung BG. (eds). Basic and clinical pharmacology. $8^{\text {th }}$ ed. Lange Medical Books/McGraw. Hill Publishing Division, New York; 2001. p. 711-34.

9. Rahman G, Syed UJ, Amanullah K, Nusrat J, Rehana R, Samiullah SNT. Effect of thyme oil on the transdermal permeation of pseudoephedrine $\mathrm{HCl}$ from topical gel. Dissolution Tech 2019;4:18-23.

10. Charles M, Simon J. Ketoprofen release from permeation across and rheology of simple gel formulation that stimulate increasing dryness. Int J Pharm 2003;268:37-45.

11. Shivhare UD, Jain KB, Mathur VB, Bhusari KP, Roy AA. Formulation development and evaluation of diclofenac sodium gel using water soluble polyacrylamide polymer. Digest J Nanomaterials Biostructures 2009;4:285-90.

12. Fathy A Dawaba, H Ahmed M, Ahmed S. Preparation, characterization, and stability studies of piroxicam loaded microemulsions in topical formulations. Drug Discoveries Ther 20104;4:267-75.

13. Rahman G, Syed UJ, Mahmood A, Syed F, Muhammad A. Extraction, formulation and characterization of an in vitro and ex-vivo evaluation of Thymus serpyllum L. (Thymus oil) from topical preparations using dialysis cellulose membrane and natural rabbit skin Pak. J Pharm Sci 2019;4:1563-70.
14. Sharma CP. Interpolymer complex microparticles based on polymethacrylic acid-chitosan for oral insulin delivery. J Appl Polymer Sci 2006;2:506-12.

15. Samiullah, Syed UJ, Rahman G, Syed J, Asmathulla. Formulation and evaluation of transdermal patches of pseudoephedrine hcl. Int J Appl Pharm 2020;3:121-7.

16. Trivedi M, Patil S, Mishra RK, Jana S. Structural and physical properties of biofield treated thymol and menthol. J Mol Pharm Org Process Res 2015;2:1-15.

17. Rahman G, Jan SU, Ahmad M, Faridullah S, Akhtar M. Formulations, characterization, in vitro and ex vivo release of Ephedra extract from topical preparations using dialysis cellulose membrane and natural rabbit skin. Dissolution Tech 2017;4:24-30.

18. Rahman G, Syed UJ, Ahmad M, Faridullah S, Akhtar M. Formulation and evaluation of topical carbamazepine semi solid dosage forms for transdermal drug delivery. Lat Am J Pharm 2019;1:121-7.

19. Rahman G, Syed UJ, Mahmood A, Muhammad A, Muhammad MQ. Formulation, characterization and in vivo evaluation of hedera helix l., topical dosage forms. Pak J Pharm Sci 2019;6:2603-8.

20. Tailane S, Anna M, Maria B. Influence of oleic acid on the rheology and in vitro release of lumiracoxib from poloxamer gels. Int J Pharm Pharm Sci 2010;2:286-302. 